\title{
Software Tools in Endoscopy - Nice to Have or Essential?
}

\author{
Oliver Möschler
}

Department of Gastroenterology, Marienhospital Osnabrück, Germany

\section{Keywords}

Software tools - Quality requirements - Endoscopy . Logistics

\section{Summary}

Background: Documentation of findings and of the treatment implications resulting from them is one of the central tasks involved in medical work. The introduction of software tools for managing and providing technical support for this task is a logical development. Methods: A literature search was conducted in September 2015 using PubMed and the search terms 'gastrointestinal endoscopy AND electronic documentation' and 'software tools AND gastrointestinal endoscopy AND documentation'. Results: The requirements in relation to documentation, patient information and sedation, dealing with histological findings, materials logistics, recording video documents, and hygiene documentation are discussed. Conclusion: Software tools are essential for managing basic documentation requirements. However, for many aspects of the documentation required in a modern endoscopy department, there are various - and sometimes substantial - gaps in the programs currently available. More intensive discussions need to take place regarding existing gaps and requirements, both with the suppliers concerned and among colleagues and specialist societies.

(c) 2016 S. Karger GmbH, Freiburg

\section{Introduction}

Documentation of findings and of the treatment implications resulting from them is one of the central tasks involved in medical work. It represents an essential basis for working with patients - in view of the often observational nature of the diagnostic process and the need to compare findings over time, due to the dynamic nature of many conditions, particularly those in the field of gastroenterology (e.g., healing of gastric ulcers), and the need to record disease conditions scientifically.

The increasing documentation requirements to satisfy legal and insurance concerns mean that there has been a massive increase in the time taken up by documentation in medical work in recent years. In 2004, the General Medical Council (Bundesärztekammer) in Germany first requested suggestions for ways of reducing the amount of documentation work in German hospitals, and it set up a working group for this purpose. This was prompted by the results of a large-scale survey showing that the daily documentation time per physician and working day was $194.9 \mathrm{~min}$. However, the reality 12 years later is that documentation tasks have in fact continued to increase substantially $[1,2]$. The introduction of software tools for managing and providing technical support for this task is thus a logical development, although there have been no surveys demonstrating that any actual reduction in the time required for documentation is achieved by introducing electronic documentation systems.

In the field of endoscopy in particular, good documentation of the findings is of vital medical importance, since in some cases a diagnostic finding can only be substantiated after considerable time and effort. In addition, further tasks such as staff planning, planning of the daily program, and materials management would also be difficult to organize without computer support.

Independently of any evaluation of various commercially available software tools, the present article discusses the issue of which software support functions are indispensable, which are useful, and which might become desirable in the future.

\section{Documentation Requirements in Endoscopy}

Initially, the question must surely be raised of whether there is any rationale at all for the purchase and use of a software tool for documentation purposes in endoscopy. After all, in the fields of both ultrasonography and endoscopy, the age of handwritten documentation of each finding is not that long ago, and written docu-

\section{KARGER}

Fax +497614520714

\section{() 2016 S. Karger GmbH, Freiburg}

$2297-4725 / 16 / 0321-0037 \$ 39.50 / 0$
Dr. Oliver Möschler

Klinik für Innere Medizin / Gastroenterologie Marienhospital

Bischofstraße 1, 49074 Osnabrück, Germany oliver.moeschler@mho.de 
mentation is sometimes still in use today in smaller institutions and practices.

Minimum documentation requirements in endoscopy have recently been set out in the level 2 consensus-based guideline 'Quality Requirements in Gastrointestinal Endoscopy', published by the German Association for Digestive and Metabolic Diseases (Deutsche Gesellschaft für Verdauungs- und Stoffwechselerkrankungen; DGVS) [3]. In addition to stating that the findings and images from endoscopic examinations used to establish each diagnosis should be reproducible, the guideline sets out the legal requirements for storage of images and for quality assurance. The parameters that have to be recorded in the documentation of an examination under the guideline requirements are listed in table 1. In addition, the certification regulations established by the German Association for General and Visceral Surgery (Deutsche Gesellschaft für Allgemein- und Viszeralchirurgie; DGAV) for the field of surgical endoscopy state that the existence of an electronic data processing system is a prerequisite for registration by the DGAV of a department as a reference center [4].

Due to the large number of parameters required in these documents, it quickly becomes clear that adequate documentation is now only possible with the help of electronic support, and currently available documentation programs must be able to meet these minimum requirements. In addition, particularly in larger endoscopy and ultrasound units, the logistic demands involved in the storage and timely recall of previous findings would now be almost impossible without computer support; the workflow would be constantly held up without such support. Given the requirement that standardized terminology and current scoring systems be used when producing reports, automatic text blocks and electronically completed forms meeting the relevant requirements are also very useful - particularly since these lead to faster and more detailed documentation in comparison with handwritten processing $[5,6]$.

There is thus no question that electronic support for documenting endoscopy and ultrasound findings is necessary. Besides being essential for processing and preparing the minimum DGVS requirements mentioned above, it has now become indispensable for any modern endoscopy and ultrasound unit.

\section{Endoscopy Going Forward: Future Documentation Requirements}

As is already evident from the DGVS minimum documentation requirements, the optimal software support needed by the staff of an endoscopy unit constantly needs to be adapted to new regulations and specifications. A few years ago, there was no necessity to record the time course of each examination, in accordance with the very detailed specifications that followed from the DGVS's time recording project; nor was it technically possible to enter details for a second nurse as is now required in the DGVS's level 3 evidencebased and consensus-based guideline on 'Sedation in Gastrointestinal Endoscopy' [7]. The 'Statutory Regulations on the Dispensing of Medical Products and Changes in Regulations for Medical Prod-
Table 1. Requirements outlined in the guideline 'Quality Requirements in Gastrointestinal Endoscopy'

1. Identification of the patient

2. Indication

3. Identification of endoscopist and nurses

4. Device type and serial number

5. Medication and dosage

6. Time recording of the examination

7. Completeness and preparation

- Completeness of the endoscopic procedure

- Invasion depth

- In cases with incomplete examination: reasons for the termination

- Grade of preparation

8. Description of endoscopic findings using standardized terminology

9. Endoscopic diagnosis and therapy

- Description of diagnostic or therapeutic interventions

- Documentation of the place of origin of histologic/cytologic specimen

- Complications of the procedure

- Recommendations for postinterventional care and follow-up

10. Documentation of DRG-related codes (ICD and OPS)

11. Documentation of the used equipment

12. Relevant images should be added to the report

ucts' introduced in Germany on July 28, 2014 with a transitional regulatory period that expired on October 1, 2015 set out new documentation requirements for the implantation of medical products (such as stents in gastrointestinal endoscopy) [8]. This is a very recent example of the way in which electronic documentation systems need to be adaptable. In hospital departments that are active in the field of interventional medicine, electronic recording of implants makes it much easier to achieve the required identification, within a period of 3 days, of all patients who have received a medical product made by a specific manufacturer, taking the statutory regulations into account.

In addition to the above examples, each department may also have its own individual arrangements and focuses, so that the systems that are available need to have a high level of technical flexibility.

\section{Requirements for Documenting Patient Information and Sedation}

The high demands on the documentation systems used result in particular from the requirements of the sedation guideline for complete documentation of the information provided to the patient regarding risks and safety, documentation of a previously sedated patient's readiness to be discharged, and documentation of vital parameters during and after the examination. Hardly any of the software programs available to date are capable of meeting these requirements fully and satisfactorily. The solutions found by individual departments usually consist of a mixture of an endoscopy documentation system - which may or may not be integrated into a wider hospital or practice information system - combined with patient information forms, monitoring records, and possibly 
forms documenting outpatient discharge management, all of which may be either scanned or kept on paper. This creates an awkward mixture of patient data stored on paper or electronically. These data may be difficult to reassemble when a patient revisits the department and questions are raised by either the treating physician or the patient, or in the case of legal disputes if complications arise.

It would therefore be desirable to expand the available software tools to include the area of patient information, with an easy-to-install interface to the automated monitoring system and copying of the vital parameters noted (blood pressure, pulse, oxygen saturation) before, during, and after the examination, as well as the parameters used to document that an outpatient is ready to be discharged.

\section{Requirements for Dealing with Histological Findings}

The electronic transfer and storage of histological findings is increasingly becoming standard practice in larger hospitals with modern hospital information systems, as part of the progression toward a 'paperless hospital'. However, storing histological data is only a small part of the important processes involved in the internal handling of the findings.

Firstly, endoscopy units need to have the technical means of tracking samples that have been taken until they reach the pathologist (i.e., what has been sent to whom). In addition, the receipt of the corresponding histological report also needs to be documented. Particularly in larger institutions, the various tissue samples are often sent to different pathologists, depending on their individual specializations. It therefore needs to be documented and ensured that each pathologist can be identified in the documentation program so that inquiries can be made about outstanding reports. Monitoring of the receipt of each pathology report is also needed to prevent any loss of reports, or at least to allow this to be noted. This surveillance of outgoing and incoming materials is an essential component of quality assurance in the handling of histological findings.

Secondly, the evaluation and validation of findings that have been received, in the context of an overview along with the endoscopic findings recorded, is a task that has so far only had inadequate electronic support. The logistic elements involved range from creating a written evaluation of the findings, to passing on that evaluation to colleagues who are providing further treatment, to issuing reminders to patients about check-up examinations that are due (a 'recall calendar' which has been shown by research studies to be helpful) - e.g., after piecemeal resection of colonic adenomas. In the author's endoscopy department, this logistic system is run by a separate secretarial office using forms and calendars stored specially in the hospital information system. Combining all the aspects of this approach by using a software tool and thereby making it easier and more widely available would help improve patient compliance with screening and check-up appointments for endoscopically diagnosed diseases and could also be expected to improve the department's external image.

\section{Requirements for Materials Logistics}

At present, the materials used during an endoscopic procedure and the serial number of the endoscope used have to be documented. It would therefore be desirable to incorporate these into the electronic patient file. In the context of increasing financial pressure and the need for cost control and cost adjustment by identifying and replacing particularly expensive consumables, materials management needs to become a more important part of computer support. This again makes electronic recording of the materials used necessary - e.g., by using bar code scanners. The usage data collected in this way would then also make it possible to identify cost drivers among consumable items and to adjust them in a targeted way. In the author's own endoscopy department, adjustments relating to polypectomy snares, injection needles, and polyp traps alone reduced materials costs for conducting a simple polypectomy by $48 \%$. However, the interfaces between purchasing, endoscopy, and computing are difficult to manage. The targeted provision and use of appropriate professional software could therefore lead to substantial improvements here. Savings could also be made in relation to the ordering system of an endoscopy unit, as a department's current stock of materials could be identified and follow-up orders could be made in a targeted way. Regular monitoring of the data by the head of the endoscopy unit, discussing them with the medical financial supervisor, and balancing them with receipts from the diagnosis-related groups (DRG) for which the hospital charges, could also help identify and achieve potential savings [9].

In Germany, performance figures provided by the Institute for the Hospital Remuneration System (Institut für das Entgeltsystem im Krankenhaus; InEK) are used as a basis for negotiations between the specialist societies and InEK regarding the appropriate remuneration for gastroenterology procedures. Particularly in hospitals that use InEK calculations, the availability of a simple way of recording materials is important in order to produce a 'case-related objective cost assignment'. This can enable hospitals to influence future economic decision-making appropriately and on the basis of solid data, in accordance with the specialist society's targets.

\section{Requirements for Recording Video Documents}

The recording of video documents that is necessary in endoscopy and ultrasonography is a logical but long-neglected form of documentation. The recording of a video sequence is the only way of realistically recording an endoscopic finding, as photographic documentation only provides a very limited perspective of the full extent of the findings. Every endoscopist is familiar with the difficulty of recording the extent of bleeding from an ulcer using a still image, as the appearance varies substantially from moment to moment. In addition, methods are increasingly being required and used for which documentation using still images is pointless. Examples include endosonography in which the extent of a condition can often only be recorded dynamically over time, and contrast ul- 
trasonography in which it is only the dynamics of contrast flow in the lesion and surrounding tissue that allow a diagnosis to be established.

A limiting factor in the documentation of video sequences is the storage capacity of each hospital's picture archiving and communication system. These systems are in any case subject to special legal requirements in relation to the period of data storage and the stability of the data. Due to these requirements, storage space is expensive. For this reason alone, as well as the lack of any medical necessity for video documentation of a standard gastroscopy identifying gastritis, full and complete documentation of all endoscopic examinations cannot be expected anytime soon.

Nevertheless, there is a need in certain situations for technical recording and storage of video sequences even beyond the areas of (endo)sonography and contrast ultrasonography. Currently, this is the case with:

- Findings that cannot otherwise be adequately recorded (e.g., extent of bleeding from an ulcer, size of a lesion in the colon before resection, etc.);

- Recordings for educational purposes - e.g., the 'Endoscopy Campus' of the German Society for Endoscopy and Imaging Procedures (Deutsche Gesellschaft für Endoskopie und Bildgebende Verfahren; DGE-BV);

- Recordings for the purpose of presentation in lectures and publications;

- Recordings for documenting the interventional approach in complex procedures.

Additions to these indications for recording video sequences might in the future include obtaining a second opinion from a specialist colleague on findings or further procedures. A colleague, even in a different region of the country, would thus be able to receive a more realistic image of the findings than would be possible with a still image, and burdensome repeat examinations of the patient could be avoided.

\section{Requirements for Hygiene Documentation}

Discussions regarding an outbreak of infectious diseases transmitted via duodenoscopes $[10,11]$ have once again underlined the importance of hygiene standards in modern endoscopy. In addition to intermittent surveillance of all endoscopes by the hospital department itself, or by an external service provider or registered laboratory, it is necessary to be able to assign each endoscope used and its processing records to the patient examined. Many suppliers of documentation software provide interfaces here for the usual devices used in mechanical endoscope processing. Unfortunately, these interfaces are sometimes unnecessarily expensive, and documentation of the device and of processing that has been carried out is instead achieved using adhesive labels attached to the patient's report document. This approach carries the risk that the written findings may be lost, with subsequent liability problems if infections occur after endoscopic procedures, and it runs counter to the idea of introducing a documentation system that is as paper-free as possible.

\section{Conclusion}

For the range of minimum requirements outlined in the DGVS's level 2 guideline on 'Quality Assurance in Gastrointestinal Endoscopy' alone, it would hardly be possible to document endoscopy findings without electronic support using software tools. These programs are therefore essential for managing basic documentation requirements. Preparing medical reports in handwritten form must be consigned to the past. However, for many aspects of the documentation required in a modern endoscopy department, there are various - and sometimes substantial - gaps in the programs currently available. It is clear that it may not be possible for all requirements to be met by a single program. However, it is difficult to understand why not a single comprehensive software tool has so far become available for histology management, for example.

More intensive discussions need to take place regarding existing gaps and requirements, both with the suppliers concerned and also among colleagues and specialist societies in order to ensure that those working in the field of endoscopy have available to them the instruments needed to manage their departments. It is only in this way that it will be possible in the future to adequately meet the requirements of hospital trusts, patients, legal institutions, and liability insurance providers.

\section{Acknowledgement}

I thank Mr. Michael Robertson for his skillful revision of the manuscript and Professor Georg Kähler, Mannheim, for his helpful comments.

\section{Disclosure Statement}

No relevant financial or nonfinancial relationships exist for Dr. Oliver Möschler. 


\section{References}

1 Blum K, Müller U: Dokumentationsaufwand im Ärztlichen Dienst der Krankenhäuser: Bestandsaufnahme und Verbesserungsvorschläge. Düsseldorf, Deutsche Krankenhausverlagsgesellschaft, 2003.

2 Bundesärztekammer: Empfehlung der Bundesärztekammer zur Qualitätssicherung in der gastrointestinalen Endoskopie. (Nach dem Beschluss des Vorstandes der Bundesärztekammer vom 17./18. Dezember 1999). Dtsch Ärztebl 2000;97:A-475-A-477. www.aerzteblatt. de/archiv/21358/Empfehlung-der-Bundesaerztekammer-zur-Qualitaetssicherung-in-der-gastrointestinalenEndoskopie-\%28Nach-dem-Beschluss-des-Vorstandesder-Bundesaerztekammer-vom-17-18-Dezember1999\%29.

3 Denzer U, Beilenhoff U, Eickhoff A, Faiss S, Hüttl P, In der Smitten S, Jenssen C, Keuchel M, Langer F, Lerch MM, Lynen Jansen P, May A, Menningen R, Moog G, Rösch T, Jakobs R, Rosien U, Vowinkel T, Wehrmann $\mathrm{T}$, Weickert U: S2k Leitlinie Qualitätsanforderungen in der gastrointestinalen Endoskopie. AWMF register no. 021-022 (online). Berlin, Deutsche Gesellschaft für Gastroenterologie, Verdauungs- und Stoffwechselkrankheiten, 2015. www.dgvs.de/leitlinien/qualitaets anforderungen-in-der-gastrointestinalen-endoskopie/.
4 Deutsche Gesellschaft für Allgemein- und Viszeralchirurgie: Ordnung. Das Zertifizierungssystem der DGAV (ZertO 4.2). Berlin, Deutsche Gesellschaft für Allgemein- und Viszeralchirurgie, 2015. www.dgav.de/ fileadmin/media/texte_pdf/zertifizierung/Zertifizierungsordnung_DGAV_4_2.pdf.

5 Gouveia-Oliveira A, Raposo VD, Salgado NC, Almeida I, Nobre-Leitão C, de Melo FG: Longitudinal comparative study on the influence of computers on reporting of clinical data. Endoscopy 1991;23:334-337.

6 Soekhoe JK, Groenen MJM, van Ginneken AM, Khaliq G, Lesterhuis W, van Tilburg AJP, Ouwendijk RJT: Computerized endoscopic reporting is no more timeconsuming than reporting with conventional methods. Eur J Intern Med 2007;18:321-325.

7 Riphaus A, Wehrmann T, Hausmann J, Weber B, von Delius S, Jung M, Tonner P, Arnold J, Behrens A, Beilenhoff U, Bitter H, Domagk D, In der Smitten S, Kallinowsky B, Meining A, Schaible A, Schilling D, Seifert H, Wappler F, Kopp I: S3-guidelines 'Sedation in Gastrointestinal Endoscopy' 2014 (AWMF register no. 021/014) (in German). Z Gastroenterol 2015;53:802842 .
8 Deutscher Bundestag: Verordnung über die Abgabe von Medizinprodukten und zur Änderung medizinprodukterechtlicher Vorschriften. Bundesgesetzblatt 2014;35:1227-1263. www.bgbl.de/xaver/bgbl/start.xav? startbk=Bundesanzeiger_BGBlestart=//*\%255B@attr $i d=\% 27 b g b l 114 s 1227 . p d f \% 27 \% 255 \mathrm{D \#}$ bgbl__\%2F\%2F*[\%40attr_id\%3D\%27bgbl114s1227. pdf\%27]_1445010721720 (last accessed December 28 2015).

9 Rosien U: Gastroenterology in the German DRG-System 2011: a critical juncture (in German). Z Gastroenterol 2011;49:550-554.

10 Verfaillie CJ, Bruno MJ, Voor in 't Holt A, Buijs JG, Poley JW, Loeve AJ, Severin JA, Abel LF, Smit BJ, de Goeij I, Vos MC: Withdrawal of a novel-design duodenoscope ends outbreak of a VIM-2-producing Pseudomonas aeruginosa. Endoscopy 2015;47:493-502.

1 Ross AS, Baliga C, Verma P, Duchin J, Gluck M: A quarantine process for the resolution of duodenoscope-associated transmission of multidrug-resistant Escherichia coli. Gastrointest Endosc 2015;82:477-483. 